\title{
Comparative proteomic network signatures in seminal plasma of infertile men as a function of reactive oxygen species
}

\author{
Ashok Agarwal ${ }^{1 *}$, Ahmet Ayaz ${ }^{1}$, Luna Samanta ${ }^{1,2}$, Rakesh Sharma ${ }^{1}$, Mourad Assidi ${ }^{3,4}$, Adel M. Abuzenadah ${ }^{3,4}$ \\ and Edmund Sabanegh ${ }^{5}$
}

\begin{abstract}
Background: Reactive oxygen species (ROS) plays a major role in the pathology of male infertility. It is an independent biomarker of sperm function. Seminal plasma is a natural reservoir of antioxidants responsible for the nourishment, protection, capacitation, and motility of sperm within the female reproductive tract resulting in successful fertilization and implantation of the embryo. A comparative proteomic analysis of seminal plasma proteins from fertile men and infertile men with varying levels of ROS was carried out to identify signature proteins involved in ROS-mediated reproductive dysfunction.

Methods: A total of 42 infertile men presenting with infertility and 17 proven fertile donors were enrolled in the study. ROS levels were measured in the seminal ejaculates by chemiluminescence assay. Infertile men were subdivided into Low ROS (0-<93 RLU/s/106 sperm; $n=11)$, Medium ROS ( $>93-500 \mathrm{RLU} / \mathrm{s} / 10^{6}$ sperm; $\mathrm{n}=17$ ) and High ROS ( $>500 \mathrm{RLU} / \mathrm{s} / 10^{6} \mathrm{sperm} ; \mathrm{n}=14$ ) groups and compared with fertile men (4-50 RLU/s/106 sperm). 4 subjects from fertile group and 4 each from the Low, Medium and High ROS were pooled. 1D gel electrophoresis followed by in-gel digestion and LC/MS-MS in a LTQ-Orbitrap Elite hybrid mass spectrometer system was used for proteome analysis. Identification of differentially expressed proteins (DEPs), their cellular localization and involvement in different pathways were examined utilizing bioinformatics tools.
\end{abstract}

Results: The results indicate that proteins involved in biomolecule metabolism, protein folding and protein degradation are differentially modulated in all three infertile patient groups in comparison to fertile controls. Membrane metallo-endopeptidase (MME) was uniformly overexpressed ( $>2$ fold) in all infertile groups. Pathway involving 35 focus proteins in post-translational modification of proteins, protein folding (heat shock proteins, molecular chaperones) and developmental disorder was overexpressed in the High ROS group compared with fertile control group. MME was one of the key proteins in the pathway. FAM3D was uniquely expressed in fertile group.

Conclusion: We have for the first time demonstrated the presence of 35 DEPs of a single pathway that may lead to impairment of sperm function in men with Low, Medium or High ROS levels by altering protein turn over. MME and FAM3D along with ROS levels in the seminal plasma may serve as good markers for diagnosis of male infertility.

Keywords: Seminal plasma, Proteome, Reactive oxygen species, Sperm function, Infertility

\section{Background}

Seminal plasma contains secretions that are derived from the testis, epididymis and male accessory glands,

\footnotetext{
*Correspondence: agarwaa@ccf.org

${ }^{1}$ American Center for Reproductive Medicine, Department of Urology,

Cleveland Clinic, Cleveland, OH 44195, USA

Full list of author information is available at the end of the article
}

including the prostate, seminal vesicles and Cowper's gland. A considerable volume of research has focused on the mechanism(s) involved in production, morphology and function of spermatozoa, however, the critical role that seminal fluid plays in imparting motility and fertilization capacity to sperm is often neglected. Seminal fluid proteins are involved in the nourishment, protection, 
capacitation, and motility of sperm within the female reproductive tract and therefore, expected to contribute to the success of fertilization [1]. For example, the fertilization-promoting peptide (FPP) in semen stimulates penetration abilities of spermatozoa promoting fertilization [2]. Seminal fluid interacts with female reproductive tract, enhances implantation rates and early embryo development [3], increases the levels of uterine granulocyte macrophage colony stimulating factor in mice (GM-CSF) [4] and upregulates the transcription factor forkhead box P3 (FOXP3) in uterine T-cells [5], thereby improving tolerance towards paternal antigens [6]. In addition, an increasing number of seminal plasma proteins, such as insulin-like growth factor-I, alpha2-macroglobulin and the encephalin degrading enzymes, have been shown to be associated with sperm motility [7-9].

A common end to numerous pathways that lead to defective sperm function is attributed to reactive oxygen species (ROS), a group of molecules with incompletely reduced oxygen atom $[10,11]$ that are capable of reacting with almost all biomolecules leading to their altered function such as inhibition/activation of enzymes. Nature has bestowed aerobic organisms with an array of antioxidant defence mechanism(s) to fight off the noxious effects of ROS. However, when their rate of generation exceeds the cell's antioxidant defence, it leads to oxidative stress. ROS are highly reactive, non-specific and autocatalytic which qualify them to be good signalling molecules. Physiological levels of ROS is necessarily maintained in all aerobic cells [12] as well as in the semen for optimal sperm function such as capacitation, motility and acrosome reaction [13, 14]. While both leukocyte and spermatozoa serve as principal sources of ROS generation in semen, the spermatozoa are more susceptible to ROS-induced damage at stake against ROS due to its rich content of polyunsaturated fatty acids and poor antioxidant capacity. The first report on harmful effects of ROS on spermatozoa was published over 60 years ago [15] and a large body of literature has provided growing support for the concept that abnormal semen parameters and sperm damage are consequences of excessive levels of ROS resulting in impaired sperm function and subfertility [10,16-19]. Consensus is growing about the clinical utility of seminal oxidative stress testing in infertility clinics $[20,21]$.

A common pathology seen in two-thirds of infertile cases is attributed to oxidative stress in semen, although by different mechanisms [22]. A previous report from our laboratory suggests that high levels of ROS could be an independent marker of male factor infertility [20]. Because proteins have many different and unique biological functions, oxidative modifications to proteins can lead to diverse functional consequences. In fact, previous reports from various laboratories, including ours, suggest global change in proteomic profile of human spermatozoa and seminal plasma under oxidative stress conditions [23-26]. Recently, we have reported the differential regulation of protein expression in infertile patients with variations in ROS levels as evidenced by global proteomic profiling [27]. Extracellular antioxidants are secreted by the male reproductive tract for minimizing oxidative stress suffered by spermatozoa throughout the posttesticular phase of sperm existence. Such protection is apparent in the epididymis [28]. However, at the time of ejaculation, spermatozoa move out of a hypoxic epididymal environment into the well-vascularized lower female reproductive tract with higher oxygen tension [29]. Although spermatozoa spend a very short period of time in seminal plasma, in order to counteract such stress, seminal plasma is well-endowed with high levels of antioxidants, almost 10 times higher than that of blood [30]. This is in line with the role of seminal plasma in protecting oxidative DNA damage of spermatozoa in the female reproductive tract [31]. Here we test the hypothesis that the seminal plasma proteome influences fertilization and implantation in infertile men with various levels of ROS. The present study is the first report on comparative proteomic analysis of seminal plasma as a function of ROS levels in infertile patients with respect to fertile donors.

\section{Methods}

\section{Clinical sample}

This prospective study is a continuation of our recently published report on spermatozoal proteins in infertile men with different levels of ROS [27]. All specimens were collected by masturbation at the Andrology Laboratory of Cleveland Clinic after 2-3 days of sexual abstinence. The Institutional Review Board of Cleveland Clinic approved the entire protocol used in the study. All subjects consented in writing to be enrolled in this prospective study. Semen samples were collected from infertile male patients with different levels of oxidative stress $(n=42)$ and healthy donors with proven fertility $(n=17)$.

\section{Inclusion/exclusion criteria}

Men in the age group of 20-40 years who attended the clinic for infertility treatment from March 2012 to March 2014 were enrolled in the study. All female partners of these infertile men were otherwise normal as evidenced by their gynecologic evaluation results on fertility assessment. Patients who suffered from a recurring fever in the 90-day period prior to semen analysis or patients with leukocytospermia, azoospermia and oligozoospermia were excluded from the study. Donors with a proven fertility within past 2 years and in the same age group as patients were included as controls. 


\section{Semen analysis}

Manual semen analysis was performed using a MicroCell counting chamber (Vitrolife, San Diego, CA, USA) to determine sperm concentration and motility after complete liquefaction of the samples for $20 \mathrm{~min}$ at $37^{\circ} \mathrm{C}$. Sperm morphology according to World Health Organization 2010 [32] was assessed in the smears of the raw semen stained with a Diff-Quik kit (Baxter Healthcare Corporation, Inc., McGaw Park, IL). Leukocytospermia was recorded when the round cell concentration was $>1 \times 10^{6} / \mathrm{mL}$ in the sample and was further confirmed by the peroxidase or the Endtz test [25]. Specimens that were positive for the Endtz test $\left(>1 \times 10^{6}\right.$ white blood cells $/ \mathrm{mL}$ ) indicative of an underlying infection were not included in the study.

\section{Reactive oxygen species (ROS) measurement}

ROS formation was measured by chemiluminescence assay in the semen using $10 \mu \mathrm{L} 5 \mathrm{mM}$ luminol (5-amino2,3-dihydro-1, 4-phthalazinedione) as the probe for 15 min using a Berthold luminometer (AutolumatPlus 953, Oakridge, TN, USA). Results were expressed as relative light units per second per million spermatozoa (RLU/sec/10 6 sperm) [33]. Samples were divided into three groups based on the ROS levels [27]:

1. Low ROS group: ROS levels $0-<93 \mathrm{RLU} / \mathrm{sec} / 10^{6}$ sperm

2. Medium ROS: ROS levels $>93-500 \mathrm{RLU} / \mathrm{sec} / 10^{6}$ sperm

3. High ROS group: ROS concentration $>500$ RLU/ sec $/ 10^{6}$ sperm

\section{Sample preparation and Protein extraction}

We analyzed 17, 14 and 11 patients respectively in the three ROS groups. However, the sperm concentration in these samples varied significantly. In proteomic studies protein concentration used has to be normalized i.e. protein contribution from the spermatozoa in each group must be similar. In other words, the sperm concentration should also be normalized, i.e. equal amount of protein contributed by similar number of spermatozoa in each patient and the fertile group. This requirement eliminated majority of the samples from being used in the proteomic analysis. In order to perform LC-MS analysis; we pooled the samples in each group. Pooling of semen samples is acceptable in proteomic analysis. Therefore, to obtain the desired concentration of protein for proteomic analysis, the minimum number of samples that could give us the maximum protein concentration and sperm concentration in each group was four, and hence this was the minimum number of samples that were pooled in each group. This was also explained in our earlier publication [27] where contribution from each subject to the pool is normalized in terms of concentration of proteins. Since it is a continuation of the previous study to establish the factors present in spermatozoa and seminal plasma responsible for infertility, seminal plasma from the same pool was used for proteomic analysis. Spermatozoa and round cells were separated from the seminal plasma by centrifugation at $\sim 10,000 \times g$ for $10 \mathrm{~min}$. The seminal plasma was checked for the presence of spermatozoa, if any, and centrifuged again to get clear seminal plasma devoid of spermatozoa. It was mixed with the protease inhibitor cocktail (Roche, Indianapolis, IN, USA) in phosphate buffer saline in order to prevent proteolysis during sample handling and again centrifuged at $\sim 10,000 \times g$ for $30 \mathrm{~min}$ to get rid of any cellular debris. Protein concentration in the seminal plasma was determined using bicinchoninic acid (BCA) kit (Thermo, Rockford, IL, USA).

\section{Global proteomics analysis}

Equal amounts of proteins from each group were resolved on a 1D SDS-PAGE. For the protein digestion, 12 bands were cut to minimize excess polyacrylamide and divided into a number of smaller pieces. The gel pieces were washed with water and dehydrated in acetonitrile. The bands were then reduced with Dithiothreitol (DTT) and alkylated with iodoacetamide prior to the in-gel digestion. All bands were digested in-gel using trypsin, by adding $5 \mu \mathrm{L}$ of $10 \mathrm{ng} / \mu \mathrm{L}$ trypsin in $50 \mathrm{mM}$ ammonium bicarbonate and incubating overnight at room temperature to achieve complete digestion. The peptides formed were extracted from the polyacrylamide in two aliquots of $30 \mu \mathrm{L} 50 \%$ acetonitrile with $5 \%$ formic acid. These extracts were combined and evaporated to $<10 \mu \mathrm{L}$ in Speedvac and then resuspended in $1 \%$ acetic acid to make up a final volume of $\sim 30 \mu \mathrm{L}$ for LC-MS analysis. The LC-MS system was a Finnigan LTQ-Orbitrap Elite hybrid mass spectrometer system. The HPLC column was a Dionex $15 \mathrm{~cm} \times 75 \mu \mathrm{m}$ internal diameter Acclaim Pepmap C18, $2 \mu \mathrm{m}, 100 \AA$ reverse phase capillary chromatography column. The extracts $(5 \mu \mathrm{L})$ were injected into the column and the peptides eluted by an acetonitrile $/ 0.1 \%$ formic acid gradient at a flow rate of $0.25 \mu \mathrm{L} / \mathrm{min}$ were introduced into the source of the mass spectrometer on-line. The microelectrospray ion source is operated at $2.5 \mathrm{kV}$. The digest was analyzed using the data dependent multitask capability of the instrument acquiring full scan mass spectra to determine peptide molecular weights and product ion spectra to determine amino acid sequence in successive instrument scans. 


\section{Data analysis}

For semen parameters, comparison was made between fertile men and patients as well as fertile men and patients in each ROS group by Wilcoxon rank sum test. Tandem mass spectra were extracted by Proteome Discoverer version 1.4.1.288. Charge state deconvolution and de-isotoping was not performed. All MS/MS samples were analyzed using Mascot (Matrix Science, London, UK; version 2.3.02), SEQUEST (Thermo Fisher Scientific, San Jose, CA, USA; version 1.4.0.288) and X! Tandem (TheGPM, thegpm.org; version CYCLONE (2010.12.01.1). Mascot, Sequest and X! Tandem were set up to search the human reference with database $(33,292$ entries) assuming trypsin as the digestion enzyme. These searches were performed with a fragment ion mass tolerance of $0.8 \mathrm{Da}$, and a parent ion tolerance of 10 parts per million (PPM). Carbamidomethylation of cysteine was specified as a fixed modification, and oxidation of methionine was specified as a variable modification.

\section{Criteria for protein identification}

To validate MS/MS-based peptide and protein identifications Scaffold (version 4.0.6.1, Proteome Software Inc., Portland, OR, USA) was used. Peptide identifications were accepted if they could be established at $>95.0 \%$ probability by the Peptide Prophet algorithm [34] with Scaffold delta-mass correction. Protein identifications were accepted if they could be established at $>99.0 \%$ probability to achieve a false discovery rate (FDR) of $<1.0 \%$ and contained at least 2 identified peptides. Protein probabilities were assigned by the Protein Prophet algorithm [35]. Proteins that contained similar peptides and could not be differentiated based on MS/ MS analysis alone were grouped to satisfy the principles of parsimony. Proteins were annotated with gene ontology (GO) terms from National Center for Biotechnology Information (NCBI) (downloaded Oct 21, 2013) [36].

\section{Quantitative proteomics}

For proteomic analysis, the relative quantity of the protein was determined by comparing the number of spectra (termed as spectral counts $\mathrm{SpCs}$ ), used to identify each protein. The total number of mass spectra ( $\mathrm{SpC}$ ) that matched peptides to a particular protein was used to measure the abundance of proteins in the complex mixture. Normalization of spectral counts using the NSAF (normalized spectral abundance factor) approach was applied prior to relative protein quantification. DEPs were obtained by applying different constraints for significance tests and/or fold-change cutoffs based on the average $\mathrm{SpC}$ of the protein from multiple runs. Appropriate filters were used to identify DEPs that were dependent on the overall abundance of the proteins. It has been reported [37] that accurate quantification and determination of real biological change is dependent on the number of SpCs and hence, different constraints have to be applied to $\mathrm{SpC}$ levels in order to circumvent the biases and maintain a constant false positive ratio (FPR) for all proteins. The abundance of the proteins was classified as High (H), Medium (M), Low (L), or Very Low (VL) based on their average spectral counts amongst the 3 replicate runs. The error observed for the $\mathrm{SpC}$ measurements is greater for lower abundant proteins compared to higher abundant proteins. Due to this, different filtering criteria were used to determine if proteins are differentially present based on the overall abundance. The spectral count distribution for these samples is given below and a majority of the proteins have SpCs less than 20. Therefore, to normalize the values, the number of spectral counts for each protein was divided by the mass [38] or protein length, to get the spectral abundance factor (SAF) [39]. Individual SAF values were normalized to one by dividing by the sum of all SAFs for proteins in the complex, resulting in the NSAF value to accurately account for run to run variation [40]. Different constraints for significance tests ( $p$ value) and/or fold change cutoffs (or NSAF ratio) were applied for these four abundance categories, as shown below:

1. Very Low abundance: spectral count range 1.7-7; $\mathrm{p} \leq 0.001$ and NSAF ratio $\geq 2.5$ for overexpressed, $\leq 0.4$ for underexpressed proteins.

2. Low abundance: spectral count range 8-19; $\mathrm{p} \leq 0.01$ and NSAF ratio $\geq 2.5$ for overexpressed, $\leq 0.4$ for underexpressed proteins.

3. Medium abundance: spectral count range between 20 and 79; $\mathrm{p} \leq 0.05$ and NSAF ratio $\geq 2.0$ for overexpressed, $\leq 0.5$ for underexpressed proteins.

4. High abundance: spectral counts $>80$; $\mathrm{p} \leq 0.05$ and NSAF ratio $\geq 1.5$ for overexpressed, $\leq 0.67$ for underexpressed proteins.

\section{Bioinformatics analysis}

Functional annotation and enrichment analysis were performed using publicly available bioinformatics annotation tools and databases such as GO Term Finder [41], GO Term Mapper, UniProt, Software Tools for Researching Annotations of Proteins (STRAP) [42], Database for Annotation, Visualization and Integrated Discovery (DAVID) (http://david.niaid.nih.gov), and proprietary software package such as IPA (Ingenuity Pathway Analysis) from Ingenuity ${ }^{\circledR}$ Systems, used to obtain consensusbased, comprehensive functional context for the large list of proteins derived from proteomic study. 


\section{Results}

\section{Semen analysis}

Sperm concentration, morphology and ROS levels were significantly different among the fertile men and infertile men. ROS levels in fertile men $(n=17)$ were within physiological limits (i.e., 4-50 RLU) whereas the infertile group $(\mathrm{n}=42)$ had significantly elevated ROS levels with respect to control and were classified on the basis of gradient in ROS levels into three groups [27]. Of the 42 infertile men, 11 men had Low ROS levels between $0-<93$ RLU/ sec $/ 10^{6}$ sperm (range $0-12.7 \mathrm{RLU} / \mathrm{sec} / 10^{6}$ sperm), $17 \mathrm{had}$ Medium ROS group levels $>93-500 \mathrm{RLU} / \mathrm{sec} / 10^{6}$ sperm (range 131.5-320.1 RLU/sec/10 ${ }^{6}$ sperm) and 14 had High ROS levels $>500 \mathrm{RLU} / \mathrm{sec} / 10^{6}$ sperm (range 924.2-9395 $\mathrm{RLU} / \mathrm{sec} / 10^{6}$ sperm). Among the different ROS groups, a significant reduction in sperm concentration (from $53.60 \pm 46.98$ to $20.02 \pm 33.45 \times 10^{6} / \mathrm{ml}$ ), motility (\%) (from $47.7 \pm 13.7$ to $34.0 \pm 17.1$ ), and morphology (\%) (from $7.7 \pm 2.6$ to $2.5 \pm 1.8$ ) was noticed in the High ROS group compared to the fertile group. Semen parameters in the other two ROS groups were comparable with the fertile group [27].

\section{Analysis of seminal plasma proteins}

A total of 841 proteins were identified in all the 4 groups studied (Additional file 1: Table S1, Additional file 2: Table S2, Additional file 3: Table S3, Additional file 4: Table S4). Control fertile group had 572 proteins compared to 544, 612 and 670 proteins identified in infertile patients with Low, Medium and High ROS levels, respectively. Out of the total proteins identified in each group, 472 (83\%), 464 (85\%), $513(84 \%)$ and 568 (85\%) proteins were identified in all the three replicates analyzed for each of control, Low, Medium and High ROS groups, respectively. Similarly, 49 (9\%), 43 (8\%), 63 (10\%) and 73 (11\%) proteins were identified in two of the three replicates of control, Low, Medium and High ROS groups, respectively. On the other hand, 51 (9\%), 37 (7\%), 36 (6\%) and $29(4 \%)$ proteins were identified in only a single replicate of analyzed groups namely, control, Low, Medium and High ROS groups. Some of the most abundant proteins present in all the four groups were albumin, lactotransferrin isoform 1 and fibronectin isoform 3 .

\section{Global expression profile of identified proteins}

The total spectral counts range for seminal plasma samples ranged from 19591 to 27654. The overall distribution of identified proteins in different groups is shown in Fig. 1. Irrespective of ROS levels and fertility status of the individual, 420 proteins were expressed across the groups while only $3,44,83$, and 78 proteins were exclusively identified in control, Low, Medium and High ROS groups, respectively (Fig. 1a.).

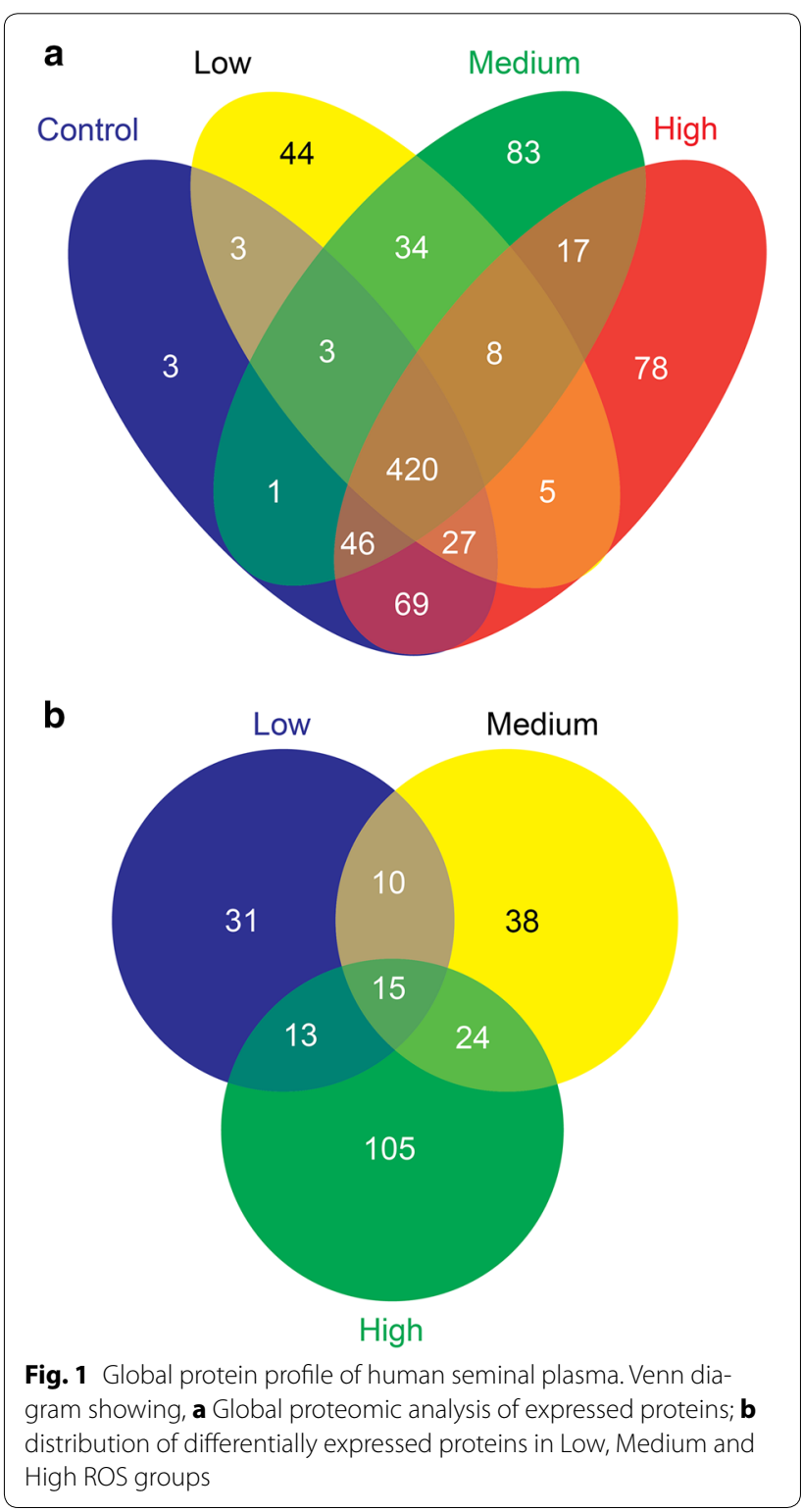

\section{Expression profile of differentially expressed proteins}

The total number of differentially expressed proteins (DEPs) as per the filtration criteria described in methods section was 236. The number of DEPs that were unique, similar or common to infertile groups with different levels of ROS in comparison to fertile control groups is shown in Fig. 1b. A total of 15 proteins are common to all the three (Low, Medium and High) infertile ROS groups when compared with control. In comparison to control, the total numbers of DEPs found are 69, 87 and 157 in case of Low, Medium and High ROS groups, respectively. Similarly the numbers of unique proteins in these groups with respect to control are 31, 38 and 105, respectively. The Low ROS group has 10 DEPs similar to Medium 
ROS and 13 DEPs similar to High ROS group while the Medium and High ROS groups have 24 similar DEPs (Fig. 1b).

The distribution of overexpressed (OE), under expressed (UE) and unique proteins in each of the three categories (i.e., Low, Medium and High ROS) and control group is shown in Fig. 2a. The numbers of proteins overexpressed in infertile group in comparison with the fertile control group were 23, 49 and 74 in Low, Medium and High ROS groups, respectively whereas the numbers of proteins underexpressed were 31, 23 and 35, respectively. Highest number (44) of unique proteins were observed in High ROS group followed by Medium (9) and the smallest for Low (7) ROS group when compared with fertile controls. On the other hand, the control group exhibited 8, 6 and 4 unique proteins in comparison
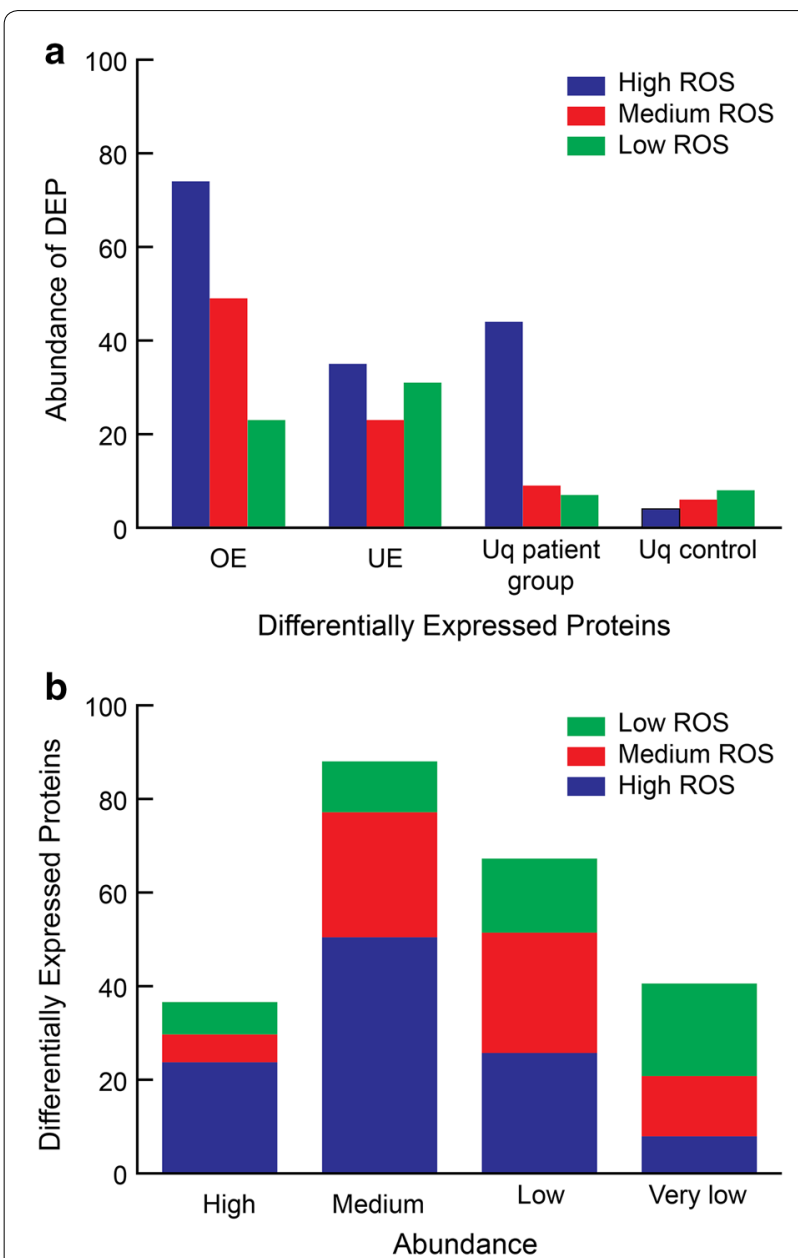

Fig. 2 Distribution and abundance of proteins in infertile men with Low, Medium and High ROS levels in comparison with control. a Over, under and uniquely expressed proteins; b High, Medium, Low and Very Low abundance proteins with Low, Medium and High ROS groups respectively. In terms of abundance, maximum numbers of high abundance proteins were identified in High ROS group (24) while in Medium and Low ROS groups 6 and 7 proteins were recorded (Fig. 2b). Similarly, 51 Medium abundance proteins were identified in High ROS group with respect to control followed by Medium (27) and Low (11) ROS group. Both High and Medium ROS groups expressed 26 Low abundance proteins while 16 Low abundance proteins were identified in Low ROS group in comparison with control. Low ROS group exhibited maximum numbers (20) of Very Low abundance proteins in comparison to control followed by Medium ROS group (13) and the list was recorded for High ROS group (8) (Fig. 2b).

\section{Functional annotations and pathway analysis}

Functional annotation and enrichment analysis from consolidated findings using publicly available bioinformatics annotation tools and databases (GO Term Finder, GO Term Mapper, UniProt, STRAP, DAVID) and proprietary software package (Ingenuity Pathway Analysis) revealed a differential expression profile of seminal plasma proteins in comparison to fertile donors (Figs. 3, 4). Seminal plasma is principally composed of secretory proteins, various peptides and proteins in membranous vesicles. With increase in the levels of ROS, a gradual increase in proteins of different cellular origin was found (Fig. 3). Proteins belonging to extracellular regions showed a gradual decline across the ROS gradient in comparison to fertile donors (Fig. 3). In Low ROS group, most of the proteins belonged to extracellular region, secretory granule, cytoplasmic vesicles, mitochondria, soluble fraction and Golgi body (Fig. 3a). In Medium ROS group, proteins integral to plasma membrane, mitochondria, cytosol and pigment granules were reported (Fig. 3b). In contrast, in High ROS group many proteins belonging to endoplasmic reticulum-Golgi intermediate compartment, organelle membrane, mitochondria, organelle lumen, cytoplasmic vesicles and membrane bound vesicles were found (Fig. 3c).

Enriched functional analysis revealed that in the Low ROS group, majority of DEP were signal peptides, proteins of the extracellular region and secreted proteins (Fig. 4a). On the other hand, proteins involved in metabolic processes were differentially expressed in Medium and High ROS groups in comparison to control (Fig. 4b, c). In general, proteins involved in metabolism and energy production, protein folding and degradation, stress response proteins were activated and those involved in acute inflammatory responses were under expressed (Table 1). It was interesting to note that out of the 15 DEPs shared by three infertile ROS groups (Fig. 1b) only 8 were consistently overexpressed (3) or underexpressed 


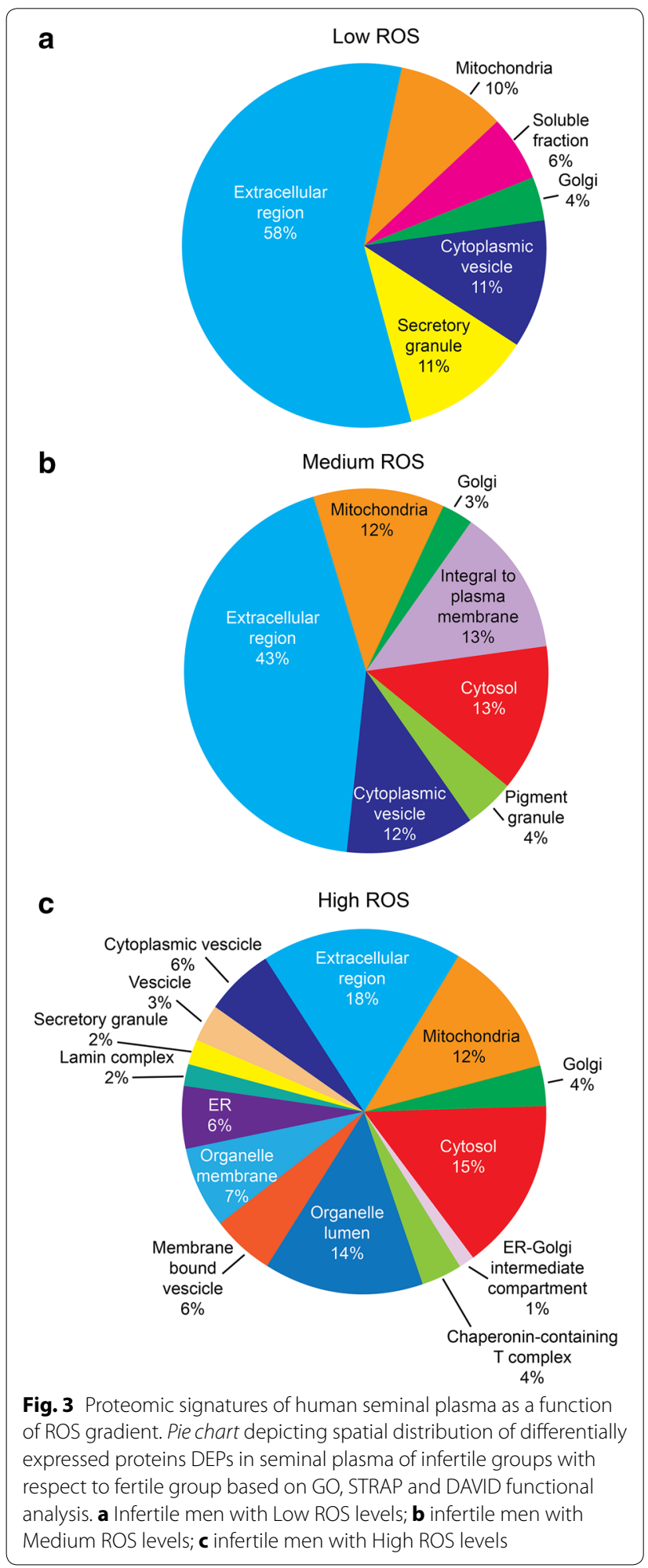

(5) in all the three infertile ROS groups in comparison to the fertile control group (Table 2). Although the mitochondrial precursor of the trifunctional enzyme subunit alpha (HADHA; a mitochondrial matrix enzyme involved in fatty acid metabolism) was overexpressed across all infertile ROS groups, its expression was markedly augmented in High ROS group ( 110 fold) in comparison to Low and Medium ROS group). Similarly, the protein FAM3D (Q96BQ1) was uniquely expressed in the fertile control group and not identified in any of the infertile group (Table 2). IPA analysis revealed that all the 35 proteins of a single biological network were overexpressed in High ROS group (Table 3; Fig. 5). A key member of the network, Neprilysin, also known as membrane metallo-endopeptidase (MME) was consistently overexpressed ( $>2$ fold) across the three infertile ROS groups (Table 2). This pathway involved proteins required for protein turnover such as proteases, chaperones, proteins involved in ubiquitination, protein imports into nucleus and mitochondria and complex macromolecular assembly. Besides, it also included mitochondrial proteins for electron transport and ATP synthesis (Fig. 5).

\section{Discussion}

The importance of seminal plasma is most often undermined and restricted to transport and protection of spermatozoa until fertilization. Possible pathways by which seminal fluid is involved in eliciting the paternal effect includes post-ejaculatory effects on spermatozoa and regulation of various female events that impact embryo development [3]. In the current investigation we report the differential expression of seminal plasma proteins as a function of ROS levels in infertile men in comparison with fertile donors. Seminal plasma proteome is as complex as that of blood plasma $[43,44]$. In the present study, comparative proteomic analysis revealed a network of protein associated with energy metabolism and protein turnover leading to reproductive dysfunction.

Global proteomic analysis revealed majority of proteins with respect to cellular distribution to be proteins of the cytoplasmic vesicles, secretory granules, soluble fraction, extracellular region, organelle membranes and membrane bound vesicles. In addition to sperm cells and soluble molecules, mammalian semen contains a variety of membranous vesicles such as prostasomes and epididymosomes, which are derived from prostatic and epididymal epithelial cells, respectively. Other tissues within the male genital tract, such as the vesicular glands, which produce the majority of seminal fluid, and the vasa deferentia, may also contribute membrane vesicles to the seminal plasma [45]. Epididymosomes are known to transfer proteins from the epididymal epithelium to passing sperm cells [46]. Many different processes have been attributed to prostasomes, including stimulation of sperm cell motility through delivery of $\mathrm{Ca}^{2+}$ signaling tools [47] and either inhibition [48] or stimulation [49] 
$\mathbf{a}$

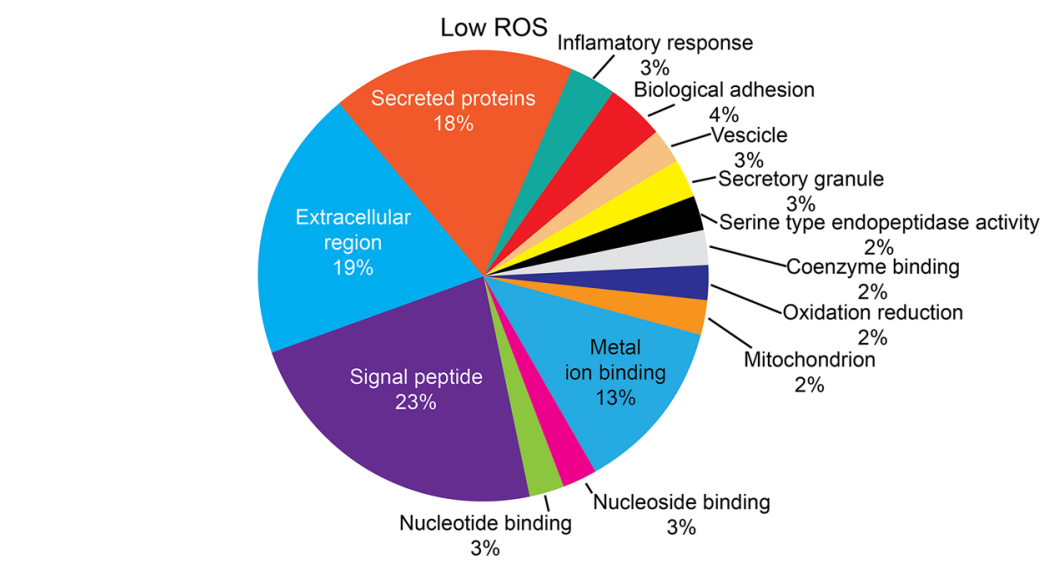

b

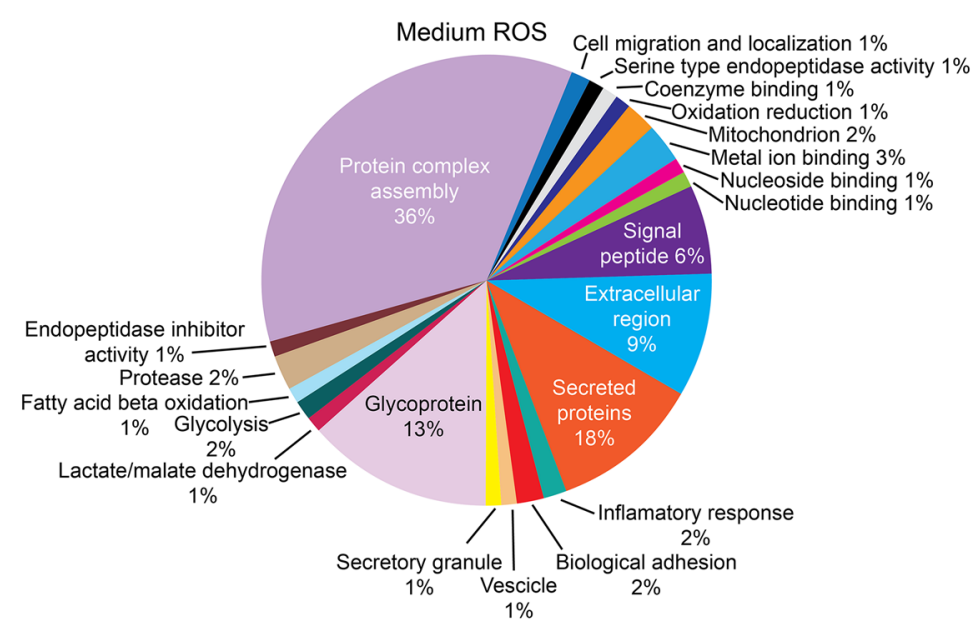

C

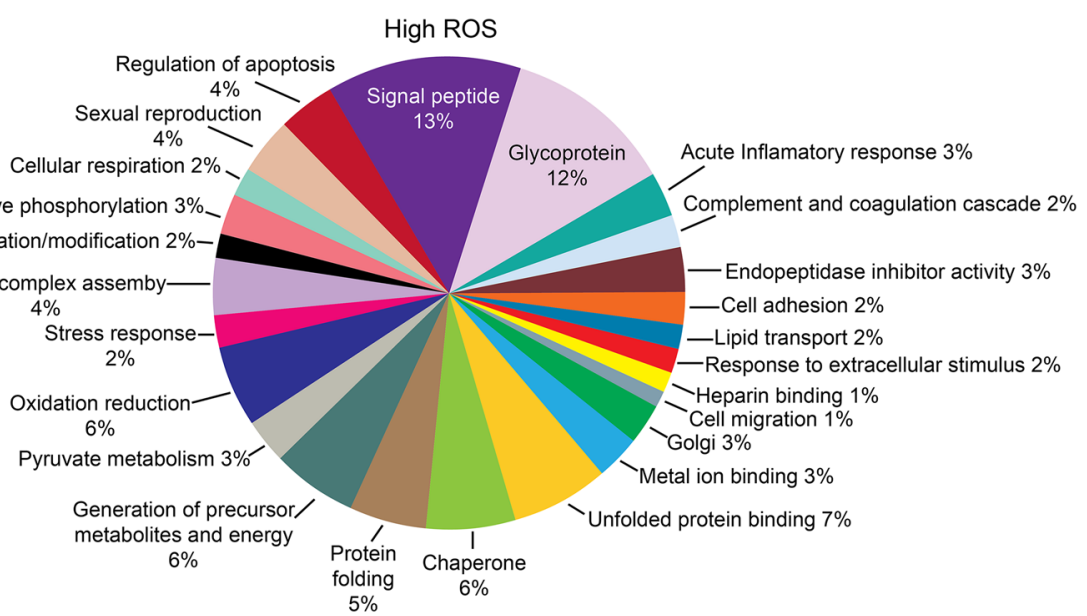

Fig. 4 Proteomic signatures of human seminal plasma as a function of ROS gradient. Pie chart depicting distribution of differentially expressed proteins (DEPS) involved in different biological processes in seminal plasma of infertile groups with respect to fertile group based on GO, STRAP and DAVID functional analysis. a Infertile men with Low ROS levels; b Infertile men with Medium ROS levels; c infertile men with High ROS levels

of the acrosome reaction. Prostasomes could also help to protect sperm cells from immune responses within the female reproductive tract by inhibiting the complement pathway [50], inhibiting lymphocyte proliferation [51], and inhibiting monocyte and neutrophil phagocytosis [52], possibly via contained immunomodulatory proteins 


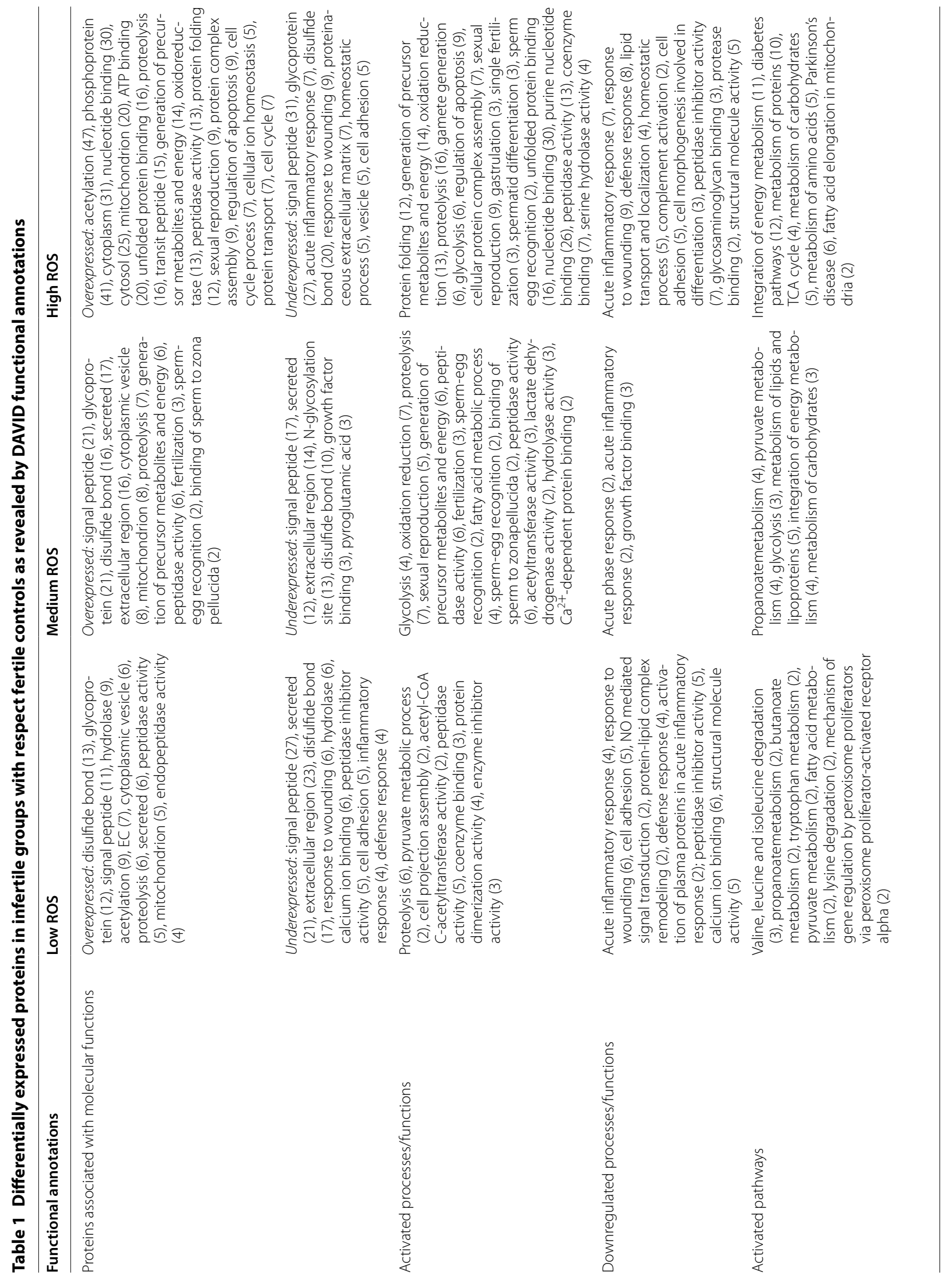




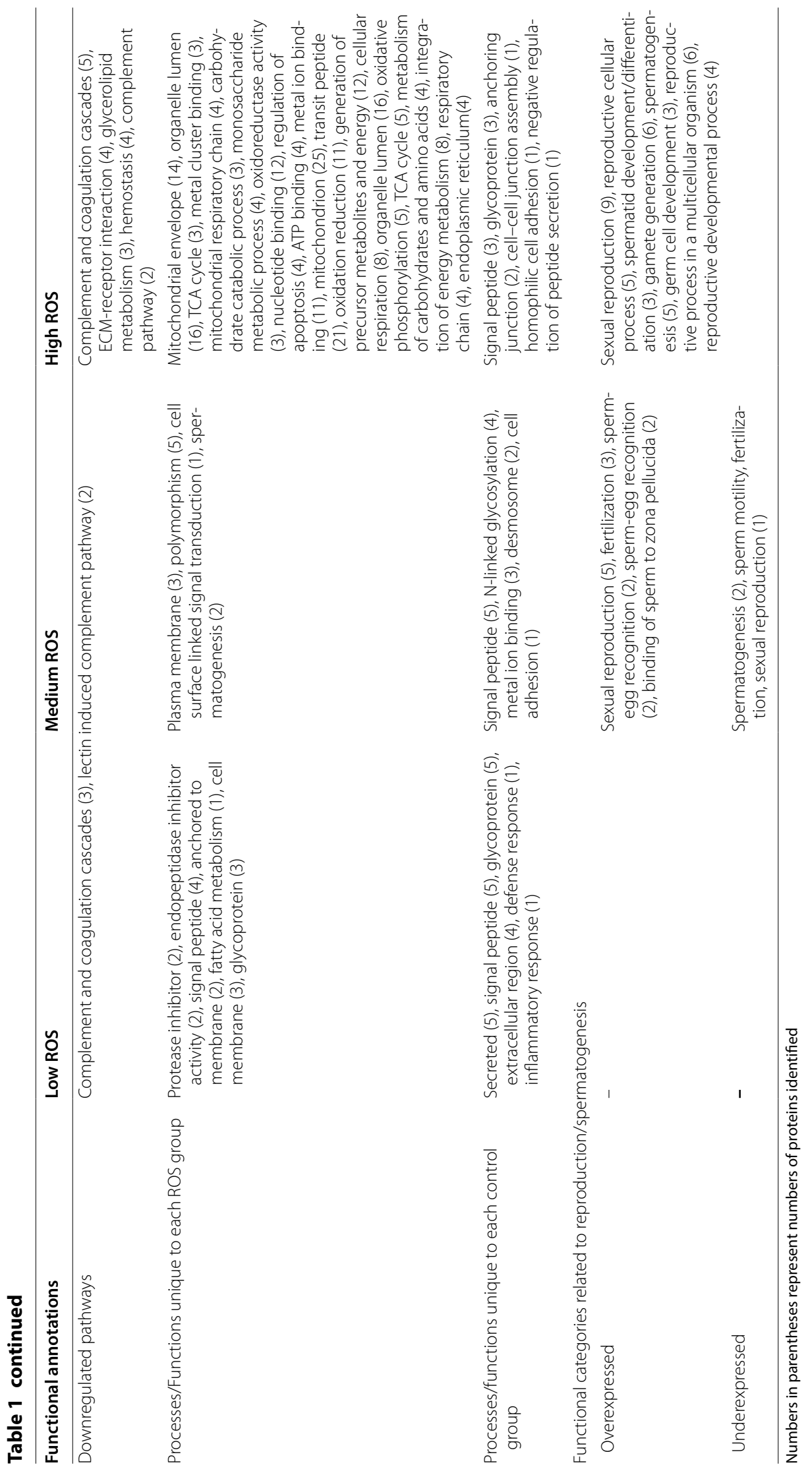


Table 2 Proteins that are uniformly under- or overexpressed in infertile ROS groups in comparison to fertile controls

\begin{tabular}{|c|c|c|c|c|}
\hline \multirow[t]{2}{*}{ Name of the gene } & \multirow[t]{2}{*}{ Name of the protein } & \multicolumn{3}{|c|}{ NSAF ratio } \\
\hline & & Low ROS & Medium ROS & High ROS \\
\hline LTBP1 & Latent-transforming growth factor beta-binding protein 3 isoform 1 precursor & 0.11 & 0.05 & 0.33 \\
\hline COL6A2 & Collagen alpha-2(VI) chain isoform 2C2 precursor & 0.15 & 0.29 & 0.22 \\
\hline GUCY1B3 & Guanylatecyclase soluble subunit beta-1 & 0.22 & 0.03 & 0.12 \\
\hline GLG1 & Golgi apparatus protein 1 isoform 2 precursor & 0.31 & 0.47 & 0.34 \\
\hline NUCB2 & Nucleobinding-2 isoform X1 & 0.54 & 0.46 & 0.6 \\
\hline FLT3 & Receptor-type tyrosine-protein phosphatase S isoform X1 & 2.12 & 2.49 & 2.5 \\
\hline MMEL1 & Neprilysin isoform X1 & 2.61 & 2.8 & 2.24 \\
\hline HADHA & Trifunctional enzyme subunit alpha, mitochondrial precursor & 24.53 & 21.49 & 110.04 \\
\hline
\end{tabular}

such as galectin 3 [53] or CD48 [54]. However, with augmented levels of ROS, more organelle fragments, mitochondrial proteins and ER-Golgi intermediates were observed in the seminal plasma in comparison to control suggesting ROS mediated cell death. In fact, a significant enhancement in the expression of proteins associated with mitochondrial electron transport chain and ATP synthesis was noticed with increasing levels of ROS in seminal plasma. Since $\sim 2 \%$ of oxygen used by mitochondrial electron transport system is incompletely reduced to ROS particularly at the site of complex-I and -III, an enhanced activity of NDUFS1 (NADH-ubiquinone oxidoreductase $75 \mathrm{kDa}$ subunit, complex-I) as reported in the present study would lead to further augmentation of ROS. Since proteins involved in acute inflammatory response are underexpressed and since all samples used in the study were leukocyte negative, it is suggested that the enhanced production of ROS in Medium and High ROS infertile group could be due to defective sperm physiology or as a consequence of systemic disease process or stress. On the other hand, the infertile group with Low ROS levels exhibited a under expression in stress response proteins. Therefore, despite low or comparable levels of ROS with fertile donors these men remain infertile. A marked increase ( 110 fold) in HADHA, mitochondrial precursor (a mitochondrial matrix enzyme) in High ROS group (Table 2) along with complex-I and proteins of ATP synthase complex (inner mitochondrial membrane proteins) further establishes the fact that there is cell death and release of mitochondrial membrane fragments into seminal plasma.

IPA analysis revealed the altered pathways involved in various functional processes. Of all the identified pathways, the one involved in protein folding, post-translational modifications and developmental disorder was the most prominent one as all the 35 focus proteins were identified in our data set and over expressed in all three categories of infertile groups (Fig. 5). These proteins include proteases, chaperones, proteins involved in ubiquitination, protein imports into nucleus and mitochondria and complex macromolecular assembly along with mitochondrial electron chain proteins and ATP synthase.

Mammalian heat shock proteins (HSPs) are molecular chaperones classified according to their molecular weight into several families and named with a suffix of number denoting their molecular weight such as HSPH (HSP110), HSPC (HSP90), HSPA (HSP70), DNAJ (HSP40), HSPB (small HSPs, sHSPs), and two chaperone in families, namely HSPD/E (HSP60/HSP10) and CCT (TRiC) [55]. These HSP families are either inducible by stress (e.g. HSPA1), constitutively expressed, or both (e.g. HSPH1, HSPA8, HSP90AA1). Expression of some HSPs is developmentally regulated or restricted to specific cells [56]. Therefore, a marked over expression in these proteins are not esoteric in infertile men with varied levels of ROS and the High ROS group expressing maximum number of these proteins in terms of fold and abundance. In fact, overexpression of 5 HSPs and 5 CCTs is noticed in High ROS infertile group (Table 3 ) whereas only one HSP each, HSPA1L and HSP90AA1 was induced in Medium and Low ROS group respectively.

Besides HSPs, proteases play an important role in protein turn over. In this study, an augmentation in various proteases was noticed with respect to ROS levels particularly ADAMTS1 and MME. Most of ADAMs are membrane-anchored glycoproteins that are comprised of a pro-domain, a metalloprotease-like domain, a disintegrin domain, a cysteine-rich region, an epidermal growth factor repeat, a transmembrane region, and a cytoplasmic domain. Fertilin, the first ADAM described, has been implicated in integrin-mediated sperm-egg binding [57]. Instead of the transmembrane region, ADAMTS-1 (ADAM metallopeptidase with thrombospondin type 1 motif, 1) has three thrombospondin (TSP) type I motifs. These are found in both thrombospondins 1 and 2 [58]. These TSP type I motifs of ADAMTS-1 are functional 


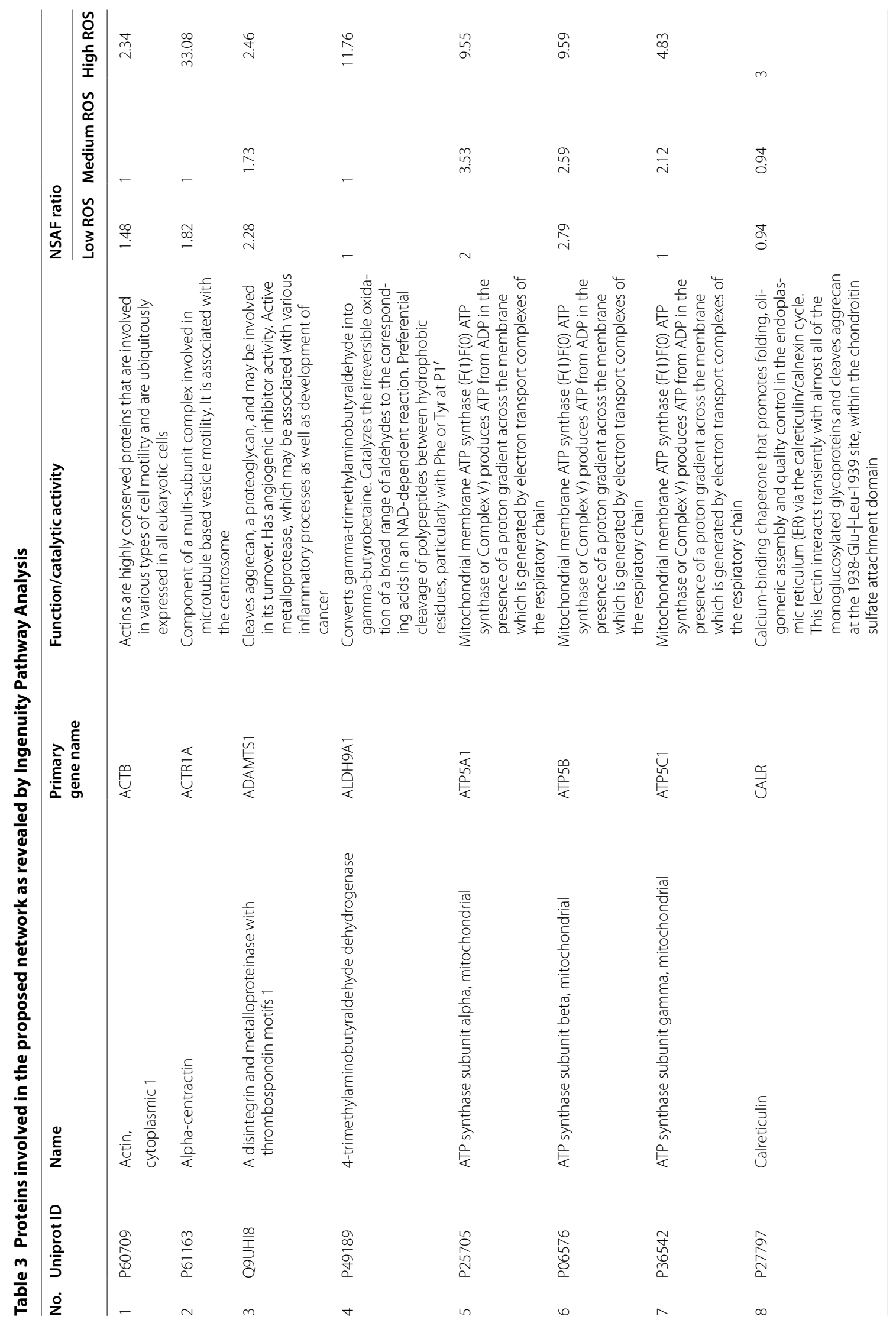




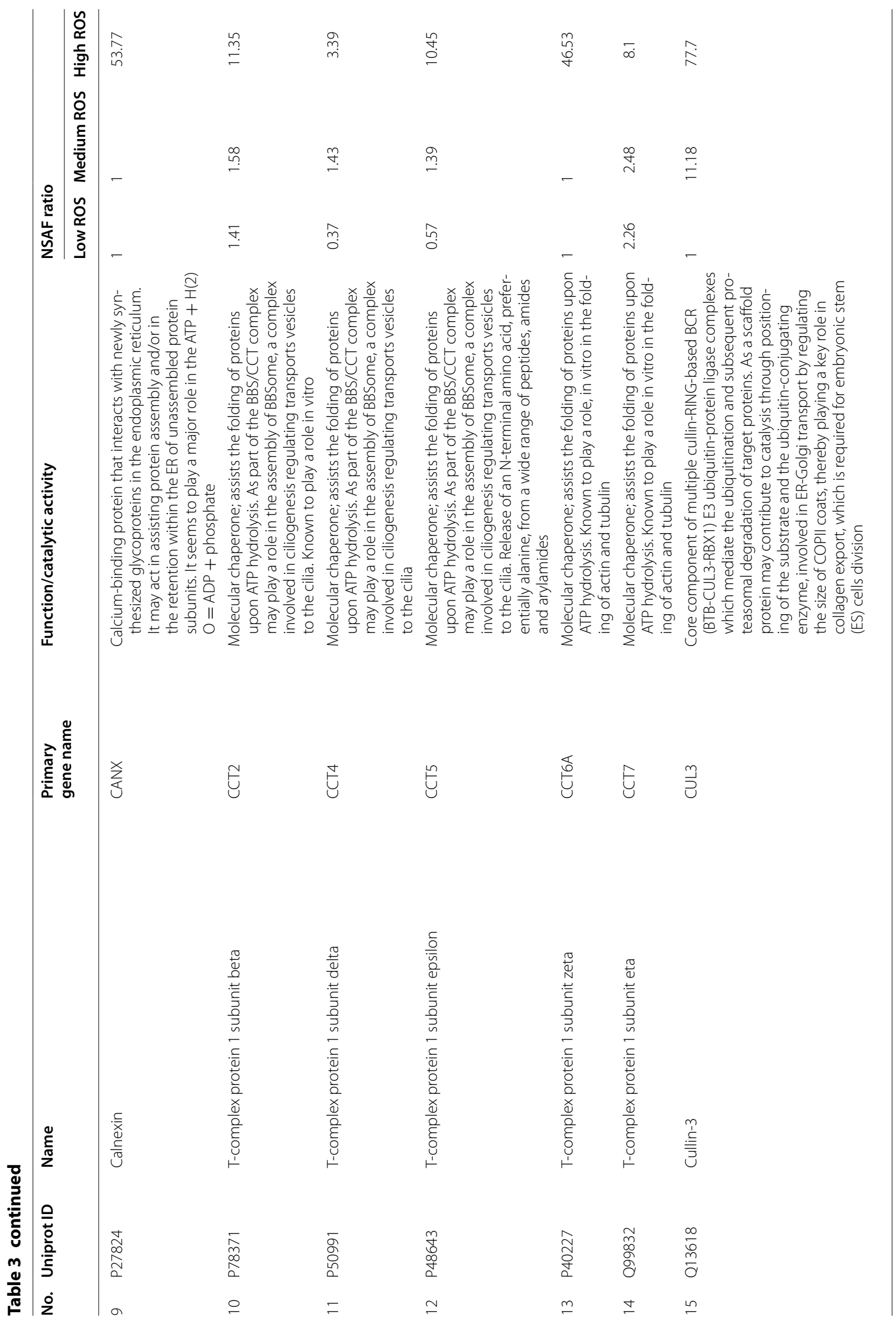




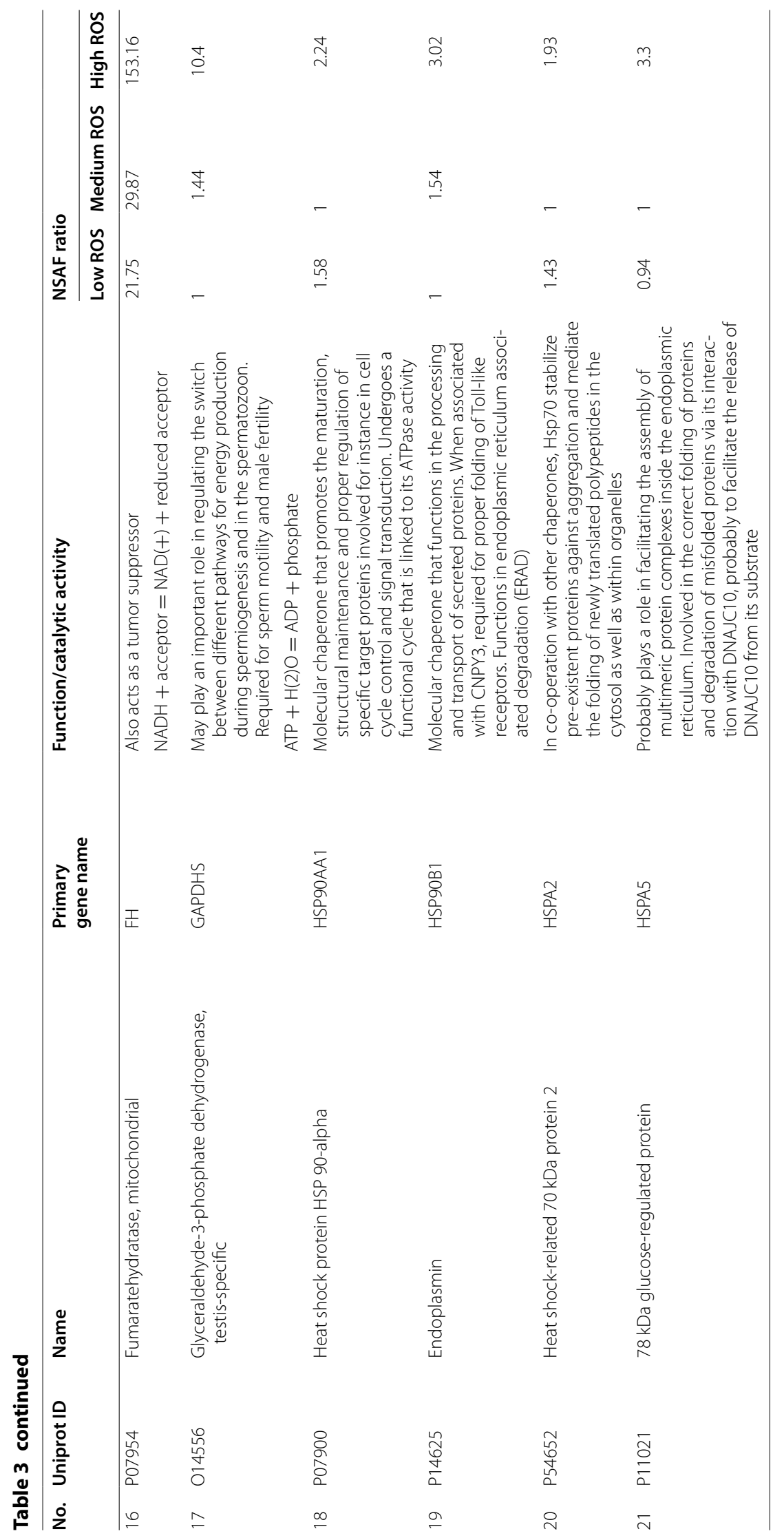




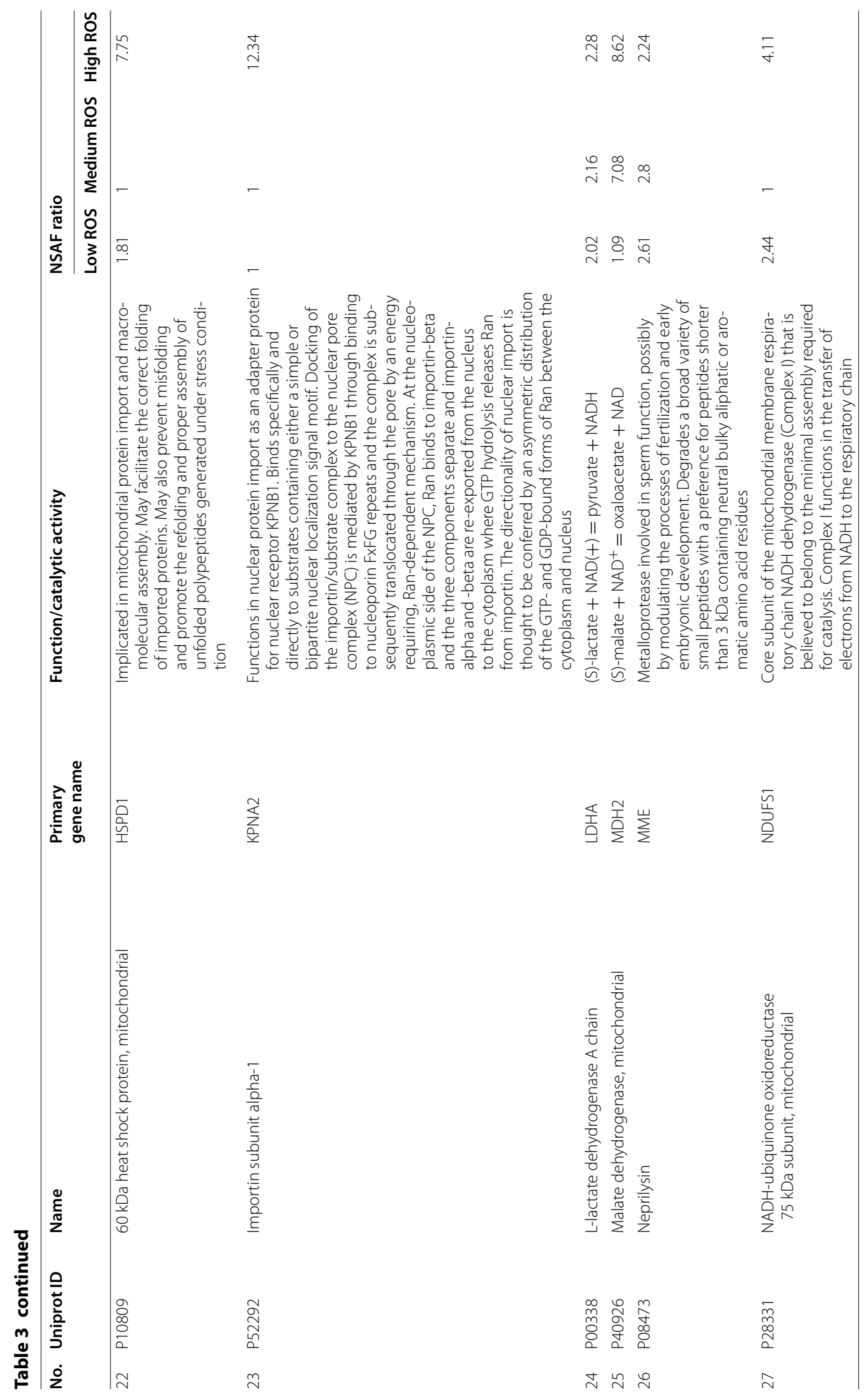




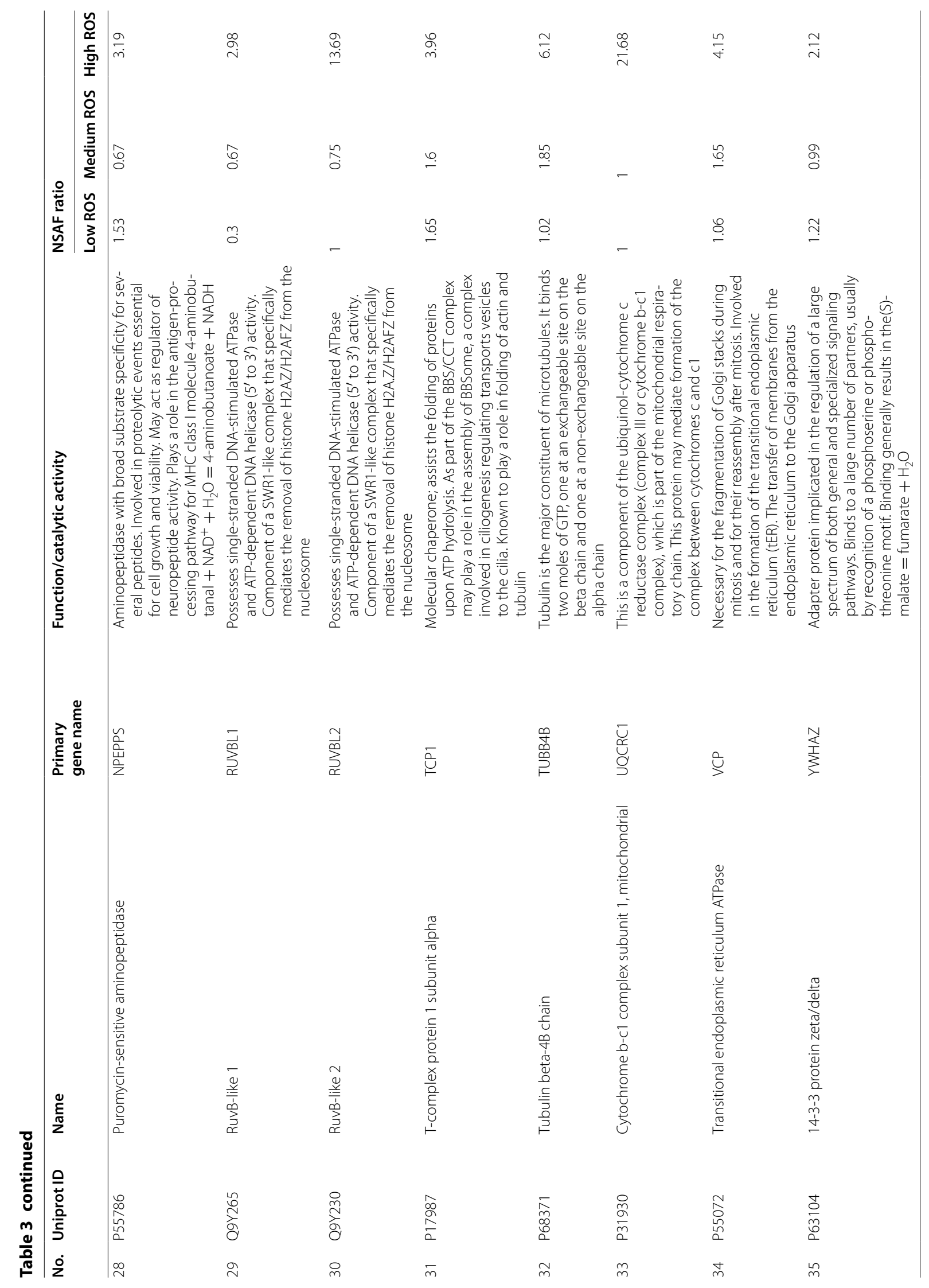




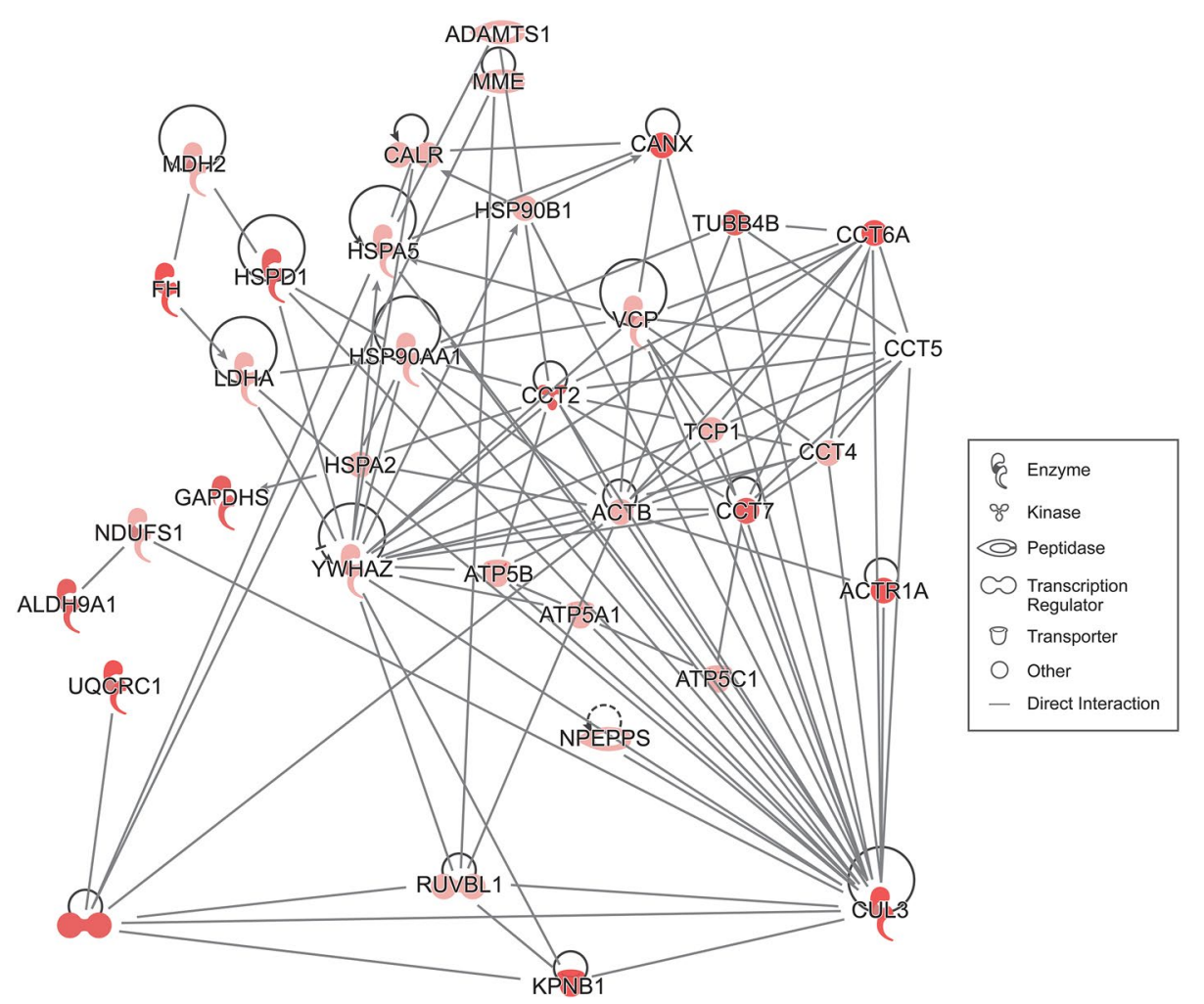

Fig. 5 IPA generated network for over expressed seminal plasma proteins in infertile men with High ROS levels. All the 35 focus molecules identified by IPA were overexpressed in the present study. Further analysis revealed that the pathway involved proteins engaged in post-translational modifications, protein folding and developmental disorder. The intensity of color of the focus molecule is proportional to their fold of expression

for binding to heparin. Kuno and Matsushima [59] have found that ADAMTS-1 is secreted and incorporated into the extracellular matrix (ECM). ADAMTS-1 cleaves the hyalectan (hyaluronan-binding proteoglycan) aggrecan between a glutamate in the P1 pocket and small aliphatic residues in $\mathrm{P}^{\prime}$. ADAMTS-1-null mice display several developmental abnormalities, primarily within the urogenital systems, affecting normal growth, organ morphology and function, and female fertility [60, 61]. A role for ADAMTS-1 in ovulation has been inferred from studies in rats [62], mice [63] and horses [64], which indicate that upregulation of ADAMTS-1 mRNA correlates temporally with the appearance of ADAMTS cleaved versican within the ECM of the cumulus oocyte complex [65]. It has been previously shown that the heparin in seminal fluid stimulates sperm capacitation in bulls. Interestingly, induction of sperm capacitation in the female reproductive tract is aided by heparin binding proteins secreted by the male accessory sex glands [66]. Seminal fluid heparin binding proteins are supposed to attach themselves to the sperm surface, especially lipids containing the phosphoryl-choline group, thus allowing heparin-like GAGs in the female reproductive tract to activate sperm capacitation [67]. Nevertheless, an over expression of ADAMTS1 will lead to excessive cleavage of heparin, rapid liquefaction of semen thereby affecting spermatozoon survival and the overall fertilization process, and this may be directly related to infertility in ROS groups.

Membrane metallo-endopeptidase (MME), also known as Neprilysin, neutral endopeptidase (NEP), cluster of differentiation 10 (CD10), and common acute lymphoblastic leukemia antigen (CALLA) is an enzyme that in humans is encoded by the MME gene. Neprilysin is a zinc-dependent metalloprotease that cleaves peptides at the amino side of hydrophobic residues and inactivates several peptide hormones including glucagon, enkephalins, substance $\mathrm{P}$, neurotensin, oxytocin, and bradykinin. MMEs are essential for development and reproduction in mammals. The activities of MME in seminal fractions are very high in comparison to other tissues (10- to 20-fold higher than in the brain) [68]. Furthermore, the activity of these enzymes is altered in men with asthenozoospermia or necrozoospermia [9]. Subiran et al. [69] have reported the presence of MME in the 
prostasomes and in the neck region of few spermatozoa. However, they observed that addition of thiorphan (analogue of encephalin that inhibits MME) maintained sperm motility at $2 \mathrm{~h}$, but this effect was not reversed by naloxone which displaces enkephalins from their receptors. This may suggest that MME regulates sperm motility by a mechanism that does not implicate the opioid system. They opined that MME could be involved in the degradation of other peptides, such as bradykinins or tachykinins, which are present in seminal fluid [70,71]. In this respect, it is interesting to note that in experiments performed with bull spermatozoa, addition of phosphoramidon, another MME inhibitor, produced an increase in sperm motility after $2 \mathrm{~h}$ of incubation, presumably by inhibition of bradykinin degradation [70]. However, in the present study, we observed a $\sim 2$ fold increase in MME in the infertile group suggesting its role in other mechanism rather than sperm motility alone since the concentration, morphology and motility was impaired in the High ROS group in comparison to fertile controls [27]. Therefore, an in depth study involving various regulators of MME activity in the seminal plasma from infertile patients with High ROS levels as well as its activity in seminal plasma from fertile men after induction of oxidative stress in vitro may shed more light on the mechanism of MME action in seminal plasma and its impact on sperm function. Since both ADAMST1 and MME inhibit angiogenesis, their enhanced activity which is principally from the prostasomes may adversely affect embryo implantation.

Alternatively, both the enzymes are cited upstream to the proteins involved in post-translational modification, protein folding and developmental disorder as revealed by IPA. Therefore, they may be responsible for altering the conformation and subsequent change in activities of key proteins having reproductive function leading to infertility. Furthermore, a secretory protein that belongs to family with sequence similarity 3 , member D (FAM3D) is uniquely expressed in fertile donors and absent in all the three infertile groups. Although not much is known about the function of this protein, it is predominantly found in placenta and it belongs to cytokine family of proteins [72]. Therefore, its role in modulating post-ejaculatory event in female reproductive tract for tolerance cannot be ruled out. Since MME is uniformly overexpressed in all the three infertile groups and FAM3D is uniquely expressed in fertile groups, it is suggested that measurement of ROS along with MME and FAM3D levels will be better markers for evaluating fertility status since a cohort of infertile patients (Low ROS group) also exhibit ROS levels comparable to fertile donors.

\section{Conclusions}

In conclusion, we have for the first time demonstrated poor sperm quality that is associated with elevated oxidative stress levels may be associated with altered protein profile of seminal plasma. Since seminal plasma is established as a vehicle for carrying proteins to the spermatozoa during post-testicular maturation phase and has a role in protection and regulation of sperm function and induction of female reproductive tract for successful fertilization and embryo implantation, altered protein expression in response to elevated ROS may impair sperm function. Further validation of DEPs is necessary to establish the role of these proteins as biomarkers of oxidative stress-induced male factor infertility.

\section{Additional files}

Additional file 1: Table S1. Identified proteins in seminal plasma of fertile men

Additional file 2: Table S2. Identified proteins in seminal plasma of infertile men with Low ROS levels

Additional file 3: Table S3. Identified proteins in seminal plasma of infertile men with Medium ROS levels

Additional file 4: Table S4. Identified proteins in seminal plasma of infertile men with High ROS levels

\section{Authors' contributions}

AA conceived the idea, supervised the study, and edited the article for submission. AAZ conducted the study and helped with the data collection and management of this study. RS helped with the writing, reviewing and editing of the manuscript. LS compiled and analyzed the data and wrote the manuscript. MA, AMA and ES helped with reviewing and editing of the manuscript. All authors read and approved the final manuscript.

\section{Author details}

${ }^{1}$ American Center for Reproductive Medicine, Department of Urology, Cleveland Clinic, Cleveland, OH 44195, USA. ${ }^{2}$ Department of Zoology, School of Life Sciences, Ravenshaw University, Cuttack, Odisha 751003, India. ${ }^{3}$ Center of Excellence in Genomic Medicine Research, King AbdulAziz University, Jeddah, Saudi Arabia. ${ }^{4}$ KACST Technology Innovation Center in Personalized Medicine at King AbdulAziz University, Jeddah, Saudi Arabia. ${ }^{5}$ Department of Urology, Cleveland Clinic, Cleveland, OH 44195, USA.

\section{Acknowledgements}

The authors are grateful to the Andrology Center technologists for scheduling the study subjects and Belinda Willard, Director, Proteomic Core Lab, Lerner Research Institute for providing assistance with proteomic analysis and Banu Gopalan, with Bioinformatics data analysis. The Orbitrap Elite mass spectrometer used in this study was purchased with funds from an NIH shared instrument grant 1S10RR031537-01 to Belinda Willard. Financial support for this study was provided by the American Center for Reproductive Medicine, Cleveland Clinic Foundation. LS thanks University Grants Commission, India for the award of Raman Post-Doctoral Fellowship.

\section{Compliance with ethical guidelines}

\section{Competing interests}

The authors declare that they have no competing interests.

Received: 7 May 2015 Accepted: 12 August 2015

Published online: 28 August 2015 


\section{References}

1. Robertson SA. Seminal plasma and male factor signalling in the female reproductive tract. Cell Tissue Res. 2005;322:43-52.

2. Fraser LR, Osiguwa OO. Human sperm responses to calcitonin, angiotensin II and fertilization-promoting peptide in prepared semen samples from normal donors and infertility patients. Hum Reprod. 2004;19:596-606.

3. Rando OJ. Daddy issues: paternal effects on phenotype. Cell. 2012;151:702-8.

4. Robertson SA, Seamark RF. Granulocyte macrophage colony stimulating factor (GM-CSF) in the murine reproductive tract: stimulation by seminal factors. Reprod Fertil Dev. 1990;2:359-68.

5. Guerin LR, Moldenhauer LM, Prins JR, Bromfield JJ, Hayball JD, et al. Seminal fluid regulates accumulation of FOXP3 + regulatory T cells in the preimplantation mouse uterus through expanding the FOXP3+ cell pool and CCL19-mediated recruitment. Biol Reprod. 2011;85:397-408.

6. Robertson SA, Guerin LR, Bromfield JJ, Branson KM, Ahlstrom AC, et al. Seminal fluid drives expansion of the CD4+ CD25+T regulatory cell pool and induces tolerance to paternal alloantigens in mice. Biol Reprod. 2009;80:1036-45.

7. Glander HJ, Kratzsch J, Weisbrich C, Birkenmeier G. Insulin-like growth factor-I and alpha 2-macroglobulin in seminal plasma correlate with semen quality. Hum Reprod. 1996;11:2454-60.

8. Wennemuth G, Schiemann PJ, Krause W, Gressner AM, Aumuller G. Influence of fibronectin on the motility of human spermatozoa. Int J Androl. 1997;20:10-6.

9. Irazusta J, Valdivia A, Fernandez D, Agirregoitia E, Ochoa C, et al. Enkephalin-degrading enzymes in normal and subfertile human semen. J Androl. 2004:25:733-9.

10. Agarwal A, Saleh RA, Bedaiwy MA. Role of reactive oxygen species in the pathophysiology of human reproduction. Fertil Steril. 2003;79:829-43.

11. Lavranos G, Balla M, Tzortzopoulou A, Syriou V, Angelopoulou R. Investigating ROS sources in male infertility: a common end for numerous pathways. Reprod Toxicol. 2012;34:298-307.

12. Holmstrom KM, Finkel T. Cellular mechanisms and physiological consequences of redox-dependent signalling. Nat Rev Mol Cell Biol. 2014;15:411-21.

13. Sharma RK, Agarwal A. Role of reactive oxygen species in male infertility. Urology. 1996;48:835-50.

14. Agarwal A, Sharma RK, Nallella KP, Thomas AJ Jr, Alvarez JG, et al. Reactive oxygen species as an independent marker of male factor infertility. Fertil Steril. 2006;86:878-85.

15. MacLeod Ahmed AH, Allamaneni SS, Comhaire FH, Agarwal A. Relationship between acrosin activity of human spermatozoa and oxidative stress. Asian J Androl. 2004;6:313-8.

16. Aitken RJ, Buckingham D, Harkiss D. Use of a xanthine oxidase free radical generating system to investigate the cytotoxic effects of reactive oxygen species on human spermatozoa. J Reprod Fertil. 1993;97:441-50.

17. Aitken RJ. A free radical theory of male infertility. Reprod Fertil Dev. 1994;6:19-23 discussion 23-14.

18. Pasqualotto FF, Sharma RK, Potts JM, Nelson DR, Thomas AJ, et al. Seminal oxidative stress in patients with chronic prostatitis. Urology. 2000:55:881-5.

19. Shen $\mathrm{H}$, Ong C. Detection of oxidative DNA damage in human sperm and its association with sperm function and male infertility. Free Radic Biol Med. 2000;28:529-36

20. Deepinder F, Cocuzza M, Agarwal A. Should seminal oxidative stress measurement be offered routinely to men presenting for infertility evaluation? Endocr Pract. 2008;14:484-91.

21. Ko EY, Sabanegh ES Jr, Agarwal A. Male infertility testing: reactive oxygen species and antioxidant capacity. Fertil Steril. 2014;102:1518-27.

22. Tremellen K. Oxidative stress and male infertility-a clinical perspective. Hum Reprod Update. 2008;14:243-58.

23. Wang G, Guo Y, Zhou T, Shi X, Yu J, et al. In-depth proteomic analysis of the human sperm reveals complex protein compositions. J Proteomics. 2013;79:114-22

24. Hamada A, Sharma R, du Plessis SS, Willard B, Yadav SP, et al. Twodimensional differential in-gel electrophoresis-based proteomics of male gametes in relation to oxidative stress. Fertil Steril. 2013;99(1216-1226):e1212.
25. Sharma R, Agarwal A, Mohanty G, Hamada AJ, Gopalan B, et al. Proteomic analysis of human spermatozoa proteins with oxidative stress. Reprod Biol Endocrinol. 2013;11:48.

26. Sharma R, Agarwal A, Mohanty G, Du Plessis SS, Gopalan B, et al. Proteomic analysis of seminal fluid from men exhibiting oxidative stress. Reprod Biol Endocrinol. 2013;11:85.

27. Ayaz A AA, Sharma R, Arafa M, Elbardisi H, Cui Z. Impact of precise modulation of reactive oxygen species levels on spermatozoa proteins in infertile men. Clin Proteomics 2015;12:4.

28. Vernet P, Aitken RJ, Drevet JR. Antioxidant strategies in the epididymis. Mol Cell Endocrinol. 2004;216:31-9.

29. Aitken RJ. Possible redox regulation of sperm motility activation. J Androl. 2000;21:491-6.

30. Rhemrev JP, van Overveld FW, Haenen GR, Teerlink T, Bast A, et al. Quantification of the nonenzymatic fast and slow TRAP in a postaddition assay in human seminal plasma and the antioxidant contributions of various seminal compounds. J Androl. 2000;21:913-20.

31. Ws O, Chen H, Chow PH. Male genital tract antioxidant enzymestheir ability to preserve sperm DNA integrity. Mol Cell Endocrinol. 2006;250:80-3.

32. Organization WH. WHO laboratory manual for the examination and processingof human semen. In: Organization WH, editor. Geneva. Switzerland:WHO Press; 2010.

33. Kashou AH, Sharma R, Agarwal A. Assessment of oxidative stress in sperm and semen. Methods Mol Biol. 2013;927:351-61.

34. Keller A, Nesvizhskii Al, Kolker E, Aebersold R. Empirical statistical model to estimate the accuracy of peptide identifications made by MS/MS and database search. Anal Chem. 2002;74:5383-92.

35. Nesvizhskii Al, Keller A, Kolker E, Aebersold R. A statistical model for identifying proteins by tandem mass spectrometry. Anal Chem. 2003;75:4646-58.

36. Ashburner M. A biologist's view of the Drosophila genome annotation assessment project. Genome Res. 2000:10:391-3.

37. Gokce E, Shuford CM, Franck WL, Dean RA, Muddiman DC. Evaluation of normalization methods on GeLC-MS/MS label-free spectral counting data to correct for variation during proteomic workflows. J Am Soc Mass Spectrom. 2011;22:2199-208.

38. Blondeau F, Ritter B, Allaire PD, Wasiak S, Girard M, Hussain NK, Angers A, Legendre-Guillemin V, Roy L, Boismenu D, Kearney RE, Bell AW, Bergeron $J$ J, McPherson PS. Tandem MS analysis of brain clathrin-coated vesicles reveals their critical involvement in synaptic vesicle recycling. Proc Natl Acad Sci USA. 2004;101:3833-8.

39. Powell DW, Weaver CM, Jennings JL, MCAfee KJ, He Y, Weil PA, Link AJ. Cluster analysis of mass spectrometry data reveals a novel component of SAGA. Mol Cell Biol. 2004;24:7249-59.

40. Zybailov B, Mosley AL, Sardiu ME, Coleman MK, Florens L, Washburn MP. Statistical analysis of membrane proteome expression changes in Saccharomyces cerevisiae. J Proteome Res. 2006;5:2339-47.

41. Boyle El, Weng S, Gollub J, Jin H, Botstein D, et al. GO:TermFinder-open source software for accessing Gene Ontology information and finding significantly enriched Gene Ontology terms associated with a list of genes. Bioinformatics. 2004;20:3710-5.

42. Bhatia VN, Perlman DH, Costello CE, McComb ME. Software tool for researching annotations of proteins: open-source protein annotation software with data visualization. Anal Chem. 2009;81:9819-23.

43. Pilch B, Mann M. Large-scale and high-confidence proteomic analysis of human seminal plasma. Genome Biol. 2006;7:R40.

44. Drabovich AP, Jarvi K, Diamandis EP. Verification of male infertility biomarkers in seminal plasma by multiplex selected reaction monitoring assay. Mol Cell Proteomics. 2011;10(M110):004127.

45. Sullivan R, Saez F, Girouard J, Frenette G. Role of exosomes in sperm maturation during the transit along the male reproductive tract. Blood Cells Mol Dis. 2005;35:1-10.

46. Frenette G, Lessard C, Madore E, Fortier MA, Sullivan R. Aldose reductase and macrophage migration inhibitory factor are associated with epididymosomes and spermatozoa in the bovine epididymis. Biol Reprod. 2003;69:1586-92.

47. Park KH, Kim BJ, Kang J, Nam TS, Lim JM, et al. Ca2+ signaling tools acquired from prostasomes are required for progesterone-induced sperm motility. Sci Signal. 2011;4:ra31. 
48. Cross NL, Mahasreshti P. Prostasome fraction of human seminal plasma prevents sperm from becoming acrosomally responsive to the agonist progesterone. Arch Androl. 1997;39:39-44.

49. Palmerini CA, Saccardi C, Carlini E, Fabiani R, Arienti G. Fusion of prostasomes to human spermatozoa stimulates the acrosome reaction. Fertil Steril. 2003;80:1181-4.

50. Babiker AA, Ronquist G, Nilsson UR, Nilsson B. Transfer of prostasomal CD59 to CD59-deficient red blood cells results in protection against complement-mediated hemolysis. Am J Reprod Immunol. 2002;47:183-92.

51. Kelly RW. Immunosuppressive mechanisms in semen: implications for contraception. Hum Reprod. 1995;10:1686-93.

52. Skibinski G, Kelly RW, Harkiss D, James K. Immunosuppression by human seminal plasma-extracellular organelles (prostasomes) modulate activity of phagocytic cells. Am J Reprod Immunol. 1992;28:97-103.

53. Jones JL, Saraswati S, Block AS, Lichti CF, Mahadevan M, et al. Galectin-3 is associated with prostasomes in human semen. Glycoconj J. 2010;27:227-36.

54. Tarazona R, Delgado E, Guarnizo MC, Roncero RG, Morgado S, et al. Human prostasomes express CD48 and interfere with NK cell function. Immunobiology. 2011;216:41-6.

55. Kampinga HH, Hageman J, Vos MJ, Kubota H, Tanguay RM, et al. Guidelines for the nomenclature of the human heat shock proteins. Cell Stress Chaperones. 2009;14:105-11.

56. Rupik W, Jasik K, Bembenek J, Widlak W. The expression patterns of heat shock genes and proteins and their role during vertebrate's development. Comp Biochem Physiol A Mol Integr Physiol. 2011;159:349-66.

57. Blobel CP, Wolfsberg TG, Turck CW, Myles DG, Primakoff P, et al. A potential fusion peptide and an integrin ligand domain in a protein active in sperm-egg fusion. Nature. 1992;356:248-52.

58. Bornstein P. Thrombospondins: structure and regulation of expression. Faseb j. 1992;6:3290-9.

59. Kuno K, Matsushima K. ADAMTS-1 protein anchors at the extracellular matrix through the thrombospondin type I motifs and its spacing region. J Biol Chem. 1998;273:13912-7.

60. Shindo T, Kurihara H, Kuno K, Yokoyama H, Wada T, et al. ADAMTS-1: a metalloproteinase-disintegrin essential for normal growth, fertility, and organ morphology and function. J Clin Invest. 2000;105:1345-52.

61. Yokoyama H, Wada T, Kobayashi K, Kuno K, Kurihara H, et al. A disintegrin and metalloproteinase with thrombospondin motifs (ADAMTS)-1 null mutant mice develop renal lesions mimicking obstructive nephropathy. Nephrol Dial Transplant. 2002;17(Suppl 9):39-41.
62. Espey LL, Yoshioka S, Russell DL, Robker RL, Fujii S, et al. Ovarian expression of a disintegrin and metalloproteinase with thrombospondin motifs during ovulation in the gonadotropin-primed immature rat. Biol Reprod. 2000;62:1090-5.

63. Robker RL, Russell DL, Espey LL, Lydon JP, O'Malley BW, et al. Progesterone-regulated genes in the ovulation process: ADAMTS-1 and cathepsin L proteases. Proc Natl Acad Sci USA. 2000;97:4689-94.

64. Boerboom D, Russell DL, Richards JS, Sirois J. Regulation of transcripts encoding ADAMTS-1 (a disintegrin and metalloproteinase with thrombospondin-like motifs-1) and progesterone receptor by human chorionic gonadotropin in equine preovulatory follicles. J Mol Endocrinol. 2003;31:473-85.

65. Russell DL, Doyle KM, Ochsner SA, Sandy JD, Richards JS. Processing and localization of ADAMTS-1 and proteolytic cleavage of versican during cumulus matrix expansion and ovulation. J Biol Chem. 2003;278:42330-9.

66. Miller DJ, Winer MA, Ax RL. Heparin-binding proteins from seminal plasma bind to bovine spermatozoa and modulate capacitation by heparin. Biol Reprod. 1990;42:899-915.

67. Miller DJ, First NL, Ax RL. Isolation and characterization of seminal fluid proteins that bind heparin. Adv Exp Med Biol. 1987;219:597-601.

68. Fernandez D, Valdivia A, Irazusta J, Ochoa C, Casis L. Peptidase activities in human semen. Peptides. 2002;23:461-8.

69. Subiran N, Agirregoitia E, Valdivia A, Ochoa C, Casis L, et al. Expression of enkephalin-degrading enzymes in human semen and implications for sperm motility. Fertil Steril. 2008;89:1571-7.

70. Siems WE, Maul B, Wiesner B, Becker M, Walther T, et al. Effects of kinins on mammalian spermatozoa and the impact of peptidolytic enzymes. Andrologia. 2003;35:44-54.

71. Ravina CG, Seda M, Pinto FM, Orea A, Fernandez-Sanchez M, et al. A role for tachykinins in the regulation of human sperm motility. Hum Reprod. 2007;22:1617-25.

72. Zhu Y, Xu G, Patel A, McLaughlin MM, Silverman C, et al. Cloning, expression, and initial characterization of a novel cytokine-like gene family. Genomics. 2002;80:144-50.

\section{Submit your next manuscript to BioMed Central and take full advantage of:}

- Convenient online submission

- Thorough peer review

- No space constraints or color figure charges

- Immediate publication on acceptance

- Inclusion in PubMed, CAS, Scopus and Google Scholar

- Research which is freely available for redistribution

Submit your manuscript at

www.biomedcentral.com/submit

C BioMed Central 